\title{
Designing On-line Chinese Language Courses: New Roles for Educators
}

\author{
Tongtao Zheng \\ Xiamen University, Fujian, China
}

\section{tongtaoz@netscape.net}

\section{Executive Summary}

The purpose of this paper is threefold. Firstly, it will review the theories and practice of on-line learning and the need for new roles in the development of new media delivery systems. Secondly, the current status of university teachers will be analyzed within the context of the new roles. And thirdly, new roles for teachers and course designers in their endeavors to assimilate information technology (IT) into on-line teaching systems are identified.

This paper suggest that most universities today still haven't fully understood the importance of IT in education and haven't adopted appropriate strategy and measurements in response to the impact of IT on education. One clear example, as pointed out by many researchers, is that universities still focus on research production and ignore the teaching practice. An immediate result from this ignorance of teaching practice is inadequate teacher education and training. This situation is getting worse with the rapid development of IT, which affects all parts of educational system.

Many universities understand the importance of online courses driven either by the idea of potential loss of future educational market share or merely wanting to cut down daily running costs. One of the strong growing areas is foreign language teaching or LOTE (Languages Other Than English) due to the impacts of educational globalization. Many websites have been set up and many LOTE course are offered online. These online language courses are designed and implemented by different teachers with various backgrounds. Many of these online courses are poorly designed. For example, some courses are identical to a textbook or have "digitalized" a textbook online. Putting a textbook online does not mean an online course. Many online language courses lack interaction; the traditional way of course delivery can be seen everywhere whereas individualization of course content can rarely be found. All these phenomena point to one source: inadequate education of teachers.

The paper suggests that a qualified Chinese online teacher should possess four macro skills: be digitally literate, be a creative thinker, be a multi-skills possessor, and be a learning facilitator. Firstly, teachers should possess adequate knowledge that is appropriate for particular purposes.

Material published as part of this journal, either on-line or in print, is copyrighted by the publisher of the Journal of Information Technology Education. Permission to make digital or paper copy of part or all of these works for personal or classroom use is granted without fee provided that the copies are not made or distributed for profit or commercial advantage AND that copies 1) bear this notice in full and 2) give the full citation on the first page. It is permissible to abstract these works so long as credit is given. To copy in all other cases or to republish or to post on a server or to redistribute to lists requires specific permission and payment of a fee. Contact Editor@JITE.org to request redistribution permission.
They also need the ability to find easily the right information from vast amounts of information sources and have the ability to evaluate such information. Secondly, a teacher should be innovative, elaborating, and a combination of the two which are essential towards his duties. Creative thinking allows us to generate alternative concepts and practices and to establish solutions effective in the ex- 
ploration and the advancement of an online course. Thirdly, online language teaching is related to work in education, computer science, natural language processing, cognitive science and psychology, linguistics, cultural studies, and media/communication studies. It is both influenced by and influences theory and research in all these related fields. It is therefore imperative that teachers have a solid grounding in the above mentioned fields. And finally, an online language teacher must be able to facilitate the transformation of their students from passive recipients to active participators.

Key words: Course design, new roles, CALL, Chinese LOTE teaching, flexible learning, interactivity, and individualization.

\section{Brief Theoretical Review of On-Line Course Development}

Computer Assisted Language Learning (CALL) is a relatively new and rapidly evolving academic field that explores the role of information and communication technologies in language learning and teaching. It includes a wide range of activities and initiatives in materials development, pedagogical practice, and research. CALL as a field began when the limitations of the computer limited the pedagogy that could be implemented on it. Consequently, some people still believe that CALL refers only to drills and mechanical exercises. Today, however, CALL provides highly interactive and communicative support for listening, speaking, reading and writing, and incorporates extensive use of the Internet. The intellectual sophistication of materials development, pedagogy and research has developed to the point where the status of CALL as an academic field requires serious consideration. CALL is no longer either a straightforward pedagogical application of a new medium, nor simply a practical extrapolation of theoretical work in some other discipline. It is a highly comprehensive instructional instrument that has the potential to replace more traditional forms of teaching.

The capacity of IT through applications like the WWW to hyperlink and layer information, provide interactivity, and support multimedia formats, makes it a valuable and exciting tool for developing, delivering and managing flexible learning programs. At its simplest, the Web is used to coordinate and manage learning, and acts as a point of communication for staff and students. At its most sophisticated level it can function as a virtual learning environment that facilitates the entire educational process. It is against this background that on-line courses in foreign languages and other subjects have emerged, gaining widespread attention and criticism.

The delivery of on-line courses in foreign languages, and in particular in a language like Chinese, is a new frontier for many LOTE (Languages Other Than English) teachers. In the past five years, many Chinese on-line courses have appeared on the Internet. Until now, however, very little information has been exchanged about the technological and educational issues involved with Chinese on-line learning. Some teachers/course designers still cannot even recognize the difference between a computer and IT. For example, they believe CALL to be little more than a computer program or CD product (Tianwei, 1990; Zhengsheng, 1999). It should come as no surprise, then, that the roles of the teacher/course designer are often neglected in the design and implementation of on-line language courses.

Educational institutions have also contributed to this state of affairs, often failing to properly assess the impact and effectiveness of the IT they have utilized in the development of their virtual teaching environments (Rami \& Gabriele, 2001). The consequence of this failure to obtain crucial course feedback information is that the multiple impact of IT and the development of an understanding of the new roles needed in this new teaching environment are neglected. The quality of on-line courses is therefore significantly reduced. As Alavi (1994) indicates, pedagogic practice 
and IT have still not been successfully integrated into curriculum and teaching activities. From time to time we can see this phenomena appear in Chinese online courses, often having a deleterious effect upon the quality and effectiveness of such courses. In an attempt to remedy this situation, it will be suggested that teachers/course designers must adopt new roles in order to develop better on-line systems.

Over the past five years, on-line Chinese courses have proliferated due to the development of various types of new IT being incorporated into the Internet. The quality of such courses, however, must be questioned. For example, many universities have developed their on-line Chinese courses with only a very limited knowledge of IT. When the services of IT professionals have been used in the development of courses, the conflict between them and the teachers/course designers has also been significant. This is because a wide knowledge gap exists between these two groups. Moreover, the Chinese teacher who is successful when teaching from the podium of a lecture theatre may not be able to repeat that success when teaching via an information system due to the change in teaching context. Finally, a wide range of educational considerations including course aims and IT capabilities places a huge burden on the course developer. Today, Chinese on-line course designers not only have to be equipped with an advanced level of language knowledge, but must also have a solid grounding in pedagogy design and wide experiences in the field of IT.

It is widely acknowledged that three forces drive 21 -century education:

1. The demand for lifelong learning due to the information explosion;

2. The need to educate all members of society, regardless of their geographical location and time constraints;

3. Employers' demand for a highly skilled workforce.

The new roles needed for teachers/course designers are closely related to the information revolution, which can be traced back to the latter part of the $20^{\text {th }}$ century. Learning is no longer limited to receiving education in traditional settings such as schools and universities. Rather, it is a lifelong journey. Traditional educational institutions are unable to accommodate the majority of societies' members. Hence, they have failed in many ways to cultivate around 25 per cent or more of their nations' populations, depending on the individual country. By implementing Internet based courses, this problem can be ameliorated. For example, more than 1500 universities that collectively enroll some 5.8 million students around the world have adopted WebCT, a special web-based courseware context and platform.

\section{New Roles Needed for University Teachers}

The new roles that must be adopted by teachers/course designers include:

1. Digital literacy;

2. Creative thinker;

3. Multi-skills possessor; and

4. Learning facilitator

\section{Digital Literacy}

Some experts argue that the digital literacy needed by teachers/course designers is comprised of the following six elements: 
1. Skills for defining the purpose of a given task;

2. Locating sources of data;

3. Selection of useful data;

4. Processing of information;

5. Presenting information;

6. Task evaluation (Dept. of Education of NSW, 1987).

Internet-based educational technology can be compared to the creation of the book, which enabled learning to shift from a purely oral to a visual and oral presentation (Anderson, 1962). The new Internet-based course is comprised of more than just assistant teaching devices used in conjunction with traditional teaching methodologies. It accelerates the information transmitting process by deploying sound effects, motion picture, graphics, text, chatrooms and Internet phones, that all serve to stimulate learning. The question that must be asked here is how these multimedia materials are selected, created and implemented into Internet courses. In 1970, it was rightly pointed out by the American Federal Commission on Instructional Technology that "examin[ing] the impact of information technology on American education in 1969 is like examin[ing] the impact of the automobile on America when the Model T Ford first came on the market." Exactly how these new skills are to be acquired is still an open question, but the known need for the new roles for teachers/course designers in education cannot be disputed.

If we are to meet the educational challenges of the $21^{\text {st }}$ century therefore, it is imperative that educational institutions successfully apply IT in their on-line course development. However, in order to realize this objective, new roles are needed for teachers/course designers. Only then can pedagogically sound courses that facilitate interaction between the learner, teacher/course designer and system, and that provide more comprehensive learning plans to suit each individual's study needs, including more flexible time frames and the accommodation of different learning rates, be achieved.

In order to take full advantage of all that technology has to offer, teachers/course designers must firstly acquire what Garfield calls "information literacy," which is defined by the Information Industry Association of the US as: "know[ing] the techniques and skills for using information tools in molding solutions to problems" (Garfield, 1979). Hershfield also coined the term "information counselor" to describe this idea. He believes that teachers/course designers must function as "diagnosticians" of patients' "medical" problems. This means, of course, that teachers/course designers must be endowed with the competence to be able to accurately diagnose the information needs of users, and to prescribe the appropriate treatments (Debons, 1980). Knowledge of what type of information is appropriate for particular purposes, how to find such information easily, and the evaluation of such information may be called information literacy or digital literacy. Paul Gilster best defines the concept in his book, Digital Literacy:

Digital literacy is the ability to understand and use information in multiple formats from a wide range of sources when it is presented via computers... (Not) only must you acquire the skill of finding things, you must also acquire the ability to use those things in your life. Acquiring digital literacy for Internet use involves mastering a set of core competencies. The most essential of these is the ability to make informed judgments about what you find on-line (Gilster, 1997. pp. 1-2). 


\section{Creative Thinker}

The two key features of successful language learning systems are interactivity and individualization (Knezevich, 1970). These can only be achieved by well-planned pedagogic plans based on CALL specific characteristics that have been developed by teachers/course designers that possess a high degree of digital literacy. Creative thinking is another vital skill that must be applied by teachers/course designers. CALL typically requires the adoption and adaptation of existing technology-based materials or learning environments to a specific course or learning program. Offthe-shelf software can rarely be used without some form of modification. Usually, significant customization and expansion are needed to integrate technology into the curriculum in a way that maximizes learning opportunities and language exposure. Knowledge about current technological applications and tools alone is not enough to ensure the above outcomes. Only the teacher/course designer who possesses both the skill of creative thinking and is au courant with technological applications and tools will be successful in this pursuit.

\section{Multi-skills Possessor}

Teachers/course designers also need to possess multidisciplinary knowledge. For example, some academics and teachers regard CALL as simply a subsection of Computer-Assisted Learning (CAL). However, because CALL deals specifically with language learning it is both inherently multidisciplinary and academically substantive. It can be said to belong to the field of applied language studies and, within that discipline itself, is most closely related to second language acquisition (SLA), which is also a rapidly evolving discipline. CALL and SLA are related to sociolinguistics, pragmatics, discourse analysis, and psycholinguistics. In addition, CALL is related to work in education, computer science, natural language processing, cognitive science and psychology, linguistics, cultural studies, and media/communication studies. It is both influenced by and influences theory and research in all these related fields. It is therefore imperative that teachers have a solid grounding in the above mentioned fields, so that they are able to assess at what stage in the learning process students' learning will best be enhanced through their interaction with computer systems. Such knowledge will also enable teachers to determine the capacity of students to respond to instruction via the computer, to help students overcome any difficulties they have in responding to this instruction, and to evaluate students' responses to the requirements of the instruction (Steinberg, 1991, p. 84). Furthermore, teachers must transform their role from being dispensers of information to "information conductors," whereby they guide rather than lead their students through the learning process.

It is also imperative that teachers/course designers broaden their knowledge outside their own traditional fields and immerse themselves in multidisciplinary knowledge in order to be assimilated into this new field. This means that educators have to understand not only how curricula are structured in order to produce effective courses, but must also comprehend the nature of IT itself. Finally, they must develop the skills to manage information, resources and IT teams. As Cohen avers, knowledge of computer science alone is not enough (Cohen \& Boyd, 1999). Or to use the terminology of Andrew Feenberg, teachers and course designers must also be equipped with "social technologies." For instance, teachers/course designers should be able to select appropriate systems and adjust them to the individual needs of their students (Feenberg, 1990).

Many educators today still lack this kind of information literacy. Teachers/course designers need to upgrade and learn their multi-skills, be willing to make major changes in their pedagogy, change their attitudes towards curriculum development, and must spend more time investigating the interaction that occurs between their students and the Internet. 
Universities and educational authorities must also support the new curriculum design and change their attitude towards teaching programs. The fact is that many universities around the world seldom offer their students well-designed courses. As Alfred points out, nearly all educational systems discourage the teacher from developing good quality curriculum materials: "...the award system in most universities does not encourage such development. Our strongest universities emphasize research; faculty time spent on curriculum development of learning material does not "count" (Bork, 1987, p. 204).

\section{Learning Facilitator}

The forces of technology bring about change not only in the roles of teachers and students within teaching and learning contexts, but also within the educational community of which they are a part. The teacher/course designer must be able to facilitate the transformation of their students from passive recipients to active participators. In addition, it is important that educational institutions do not allow IT to determine their curricula. Rather, they should first design their curriculum, and then see how IT can be used to achieve their curriculum goals (Kirk, 1988).

CALL frontiers are continually expanding into new areas that many teachers may not fully realize, drawing on theories from related fields and creating their own theoretical and methodological paradigms. Terminology has been standardized, points of reference established, and research is organized in a significant number of sub-branches of CALL. New research into CALL is therefore necessary, and may lead to qualitative studies such as the description of new learning environments, student responses to program interface options, reactions to diverse modes of presenting information, and mapping of student usage patterns within learning environments. It may also lead to quantitative studies such as the testing of the acquisition of phonological and syntactic elements, the systematic investigation of psycholinguistic and sociolinguistic variables and their effect on learning with technology, and statistical analysis of the effectiveness of alternative instructional strategies. All these new fields constitute serious challenges to teachers/course designers.

Today, teachers/course designers must also possess the ability to communicate with students, IT representatives, and university administration. As Nick Evans so cogently argues, "how good an expert each one is depends on his ability to communicate his accumulated knowledge to the rest of us" (Evans, 1986, p. 100). Until recent years, due to the prominence of the teacher-centered paradigm, it has not been necessary for teachers to communicate well with students. Nor has it been necessary for teachers to communicate with other professionals in related fields. Today, however, interpersonal communication skills play a vital role in virtual learning environments.

A better way of viewing the new roles of IT in education may be to investigate just how this new and powerful force brings a new way of thinking to educational organizations. IT in education is not just a combination of hardware and software, joined together and used by educators. It is a force that casts new light into educators' minds, forcing them to re-evaluate their concepts towards teaching and learning. It changes educators' ways of thinking in terms of their attitudes towards students, course material, course design, new curriculum for their students, and educational administration. It also demands that educators readjust their relationships with IT professionals, or become "semi-IT literate" themselves. For example, in order to be able to identify "human information needs" and "human information seeking behavior" that will enable students to use IT to retrieve information and develop correct behavior in seeking and solving problems, educators must either work closely with IT professionals, or master such skills themselves (Rathswohl, 1990).

However, the appearance of these new roles for teachers/course designers has been shown to create some negative effects in terms of the management or integration of these roles in the educa- 
tion process. Moreover, as it has been stated before, the shortage of "new-type teachers" (i.e. teachers skilled in the field of IT) is an urgent issue for current university education (Cohen \& Boyd, 1999). For example, the introduction of on-line courses into universities and other educational institutions will create instability within the operations of these institutions. The implication of this is that such institutions will only be able to maintain stability at the expense of facilitating change and adjustment. The changing of roles in the past has given birth to immense controversies. For example, Stephen and Glen claim that such change may cause "technological pollution" (Knezevich, 1970) if institutions are incapable of assimilating new technologies into teaching processes. If IT is to be successfully incorporated into teaching processes, adequate organizational environments are crucial to this success.

More than 25 years ago, Alfred Bork began to use computers in teaching first physics, and then mathematical reasoning. Bork suggested that computers would change the roles of teachers and IT professionals in terms of their impact on the whole educational system (Bork, 1978). Bork also uses computers to provide a more favorable learning environment for students, and to boost students' motivation and performance. As he noticed in the U. S: "Every young child frequently shows little interest in education, reflecting widespread parental attitudes" (Bork, 1987, p. 7). Dennis further suggests that CALL can help to change students' traditional indifference towards learning (Adams, 1985, p. 79). As a result of this change, "We may see a decreased role of the formal school and university in our educational system. Much education will be able to take place in the home in a flexible fashion (Rami \& Gabriele, 2001)."

Bork proposes that the ideal teacher for the new century is the "tutor-type teacher," because the most ideal learning model is the so-called "tutorial learning" model, which was first employed by Socrates some 2500 years ago. Though often effective, such a method of teaching is also extremely expensive. However, with the appearance of modern digital and communication technologies, the use of this learning model has become a realistic possibility. Today, if a teacher would like to become a good "tutor," s/he must receive effective training in both the education and IT fields. As the current situation stands, however, "efforts at educating the teacher in something called 'technology' are typically unsuccessful because the technology is not tied down to pedagogical situations" (Bork, 2000). Teachers are crucial to the success and proper implementation of any new learning technology. In order to successfully implement CALL, teachers must first change their attitudes, as they "often react to any form of openness, lack of structure and independent students' activities, as a threat to discipline." Therefore, in order to change teachers' attitudes, it is necessary to build a system that encourages teachers to become experts in, and enthusiasts about the computer (Adams, 1985, p. 37). Teachers must also be trained along with every new course that is developed. The most important aspect for learners is that one must be able to direct one's own learning. In order to do this, it is vital that the curriculum is both interesting, and that it accommodates the study goals of the individual.

\section{Reflections on the Lack of the New Roles in the University}

There are three major problems that can be identified with university teachers:

1. Lack of interactivity;

2. Lack of individualization;

3. Lack of multimedia features.

Problems with interactivity and individualization were succinctly summarized by Paulo Freire: 
Education thus becomes an act of depositing, in which the students are the depositories and the teacher is the depositor. Instead of communicating, the teacher issues communiqués and makes deposits which the students patiently receive, memorize, and repeat...apart from inquiry...the individual cannot be truly human. Knowledge emerges only through invention and reinvention (Freire, 1993, as cited in Bork, 1999, p.40).

The majority of on-line courses adhere to the so-called "Information Transfer" paradigm of teaching, offering little more than a reproduced version of a teacher's lecture notes. The only noticeable difference between on-line and traditional courses is that a lecturer in a classroom delivers, while the other is put on the Web. This form of information transmission, in which students are treated as the passive receivers of data, neither stimulates the desire by students to learn, nor cultivates learners' problem solving skills.

With the exception of Macquarie University, nine of the on-line courses surveyed are using only HTML to implement their programs. Because HTML is originally only a system for organizing and tagging elements of a document, it does not specify any particular formatting. Rather, it specifies only the rules for tagging elements and interprets tags to format elements in certain ways. HTML will not help course designers to achieve the goals of interactivity and individualization if used alone.

Most of the courses reviewed also suffer from a lack of asynchronous and synchronous design. At most they only include a problem report e-mail address for students who have major problems with the website. Meaningful and stimulating exchange between the learner and the on-line course is non-existent! This is a far cry from Bork's assertion that students should "do something meaningful, such as answering a question, at intervals of no longer than twenty seconds" (Adams, 1985, p.37).

As a result of the inadequate design of the courses' feedback mechanisms, the facilitator role of the teacher cannot and is not realized. Most of the courses lack interactivity in the course design itself. For example, auto grading, file submission, student record tracking, and on-line study monitoring systems are not incorporated into the courses. Neither is some form of communication software such as the whiteboard, chatrooms, self-testing exercises, and discussion forums. Because of these shortcomings, teachers are unable to monitor students' progress and pinpoint language difficulties learners may be experiencing. Teachers therefore do not have the capacity to facilitate students' learning. The chronic lack of communication between teachers and students prevents this facilitating role from occurring.

Other phenomena also indicate course designers' inadequate levels of both digital literacy and creativity. For example, they often copy or "borrow" other universities' on-line courses rather than creating their own. This kind of "laziness" can only be explained in terms of a lack of technological knowledge or digital literacy. Why else would universities with reputations such as Harvard and Oxford settle for simply borrowing other universities' curricula? Course designers' lack of digital expertise is also reflected in their inability to integrate other universities' courses with their own. This incompetence is soon exposed when one makes an examination of most of the on-line courses which all cross list with other university curricula.

Another problem that the ten courses reviewed share in common is a lack of individualization. These courses ignore the individual cognitive and learning styles of students, and fail to adopt individual instructional strategies. With the exception of the Ohio State University course, all of the courses reviewed do not have individualized programs that are tailored to satisfy the needs of different types of students. 


\section{Suggested Guidelines for the Future Development of the Ideal On-Line Language Learning Model}

Bork in an interview with the Education Review suggested that the ideal on-line language learning model will have three major elements:

1. Interactivity;

2. Individualization;

3. Multimedia. (Bork, 1999)

Students will be able to study at anytime, from anywhere and at any pace. The course must be designed to stimulate student's learning desires, must be adjusted to his/her learning style and strategies, while the frequency of interaction between teacher and student must be adequate enough to ensure that the student will not lose interest or attention during the learning process. Efficient asynchronous and synchronous communication channels also need to be established so that students will be able to communicate with the teacher and peer group at any time, and to receive feedback when required. Such a system will enable the teacher to identify students' learning progress, and to help students modify their learning strategies and study plan accordingly, thus facilitating student learning. In order to fully integrate modern technology into the curriculum, an on-line course must also have multimedia features, which have the capability to simulate the best human learning procedure - a tutorial-like learning system. By producing lifelike human-tohuman speech, transmitting visual clues, and conveying body language, course designers will be able to create a variety of individualized learning systems suited to the needs of all learners.

The most positive recent examination of the importance of new roles for those professionals involved in the field of on-line learning is that conducted by the IEEE Learning Technology Standards Committee (LTSC). The committee's scope and purpose is defined in the following passage:

This standard will specify the syntax and semantics of a 'Learner Model,' which will characterize a learner (student or knowledge worker) and his or her knowledge/abilities. This will include elements such as knowledge (from course to fine-grained), skills, abilities, learning styles, records, and personal information. This standard will allow these elements to be represented in multiple levels of granularity, from a coarse overview, down to the smallest conceivable sub-element. The standard will allow different views of the Learner Model (learner, teacher, parent, school, employer, etc.) and will substantially address issues of privacy and security. (IEEE, 2001)

According to the recommendations of the LTSC, the ideal on-line learning system must:

- Enable learners (students or knowledge workers) of any age, background, location, means, or school/work situation to create and build a personal Learner Model, based on a National standard, which they can utilize throughout their education and work life.

- Enable courseware developers to develop materials that will provide more personalized and effective instruction.

- Provide educational researchers with a standardized and growing source of data.

- Provide a foundation for the development of additional educational standards, and to do so from a student-centered learning focus.

- Provide architectural guidance to education system designers.

In other words, teachers and course designer must be able to understand the above issues and be able to research, design, and implement this kind of learning system. In conclusion, the new roles 
needed for educators in the future are of such pressing importance that no one can ignore them. As Alfred Bork so convincingly argues, universities will die in thirty years because of their inability to compete successfully with private companies when they begin to enter the education market with interactive and individualized courses. (Bork, 1999)

\section{References}

Adams, D. M. (1985). Computers and teacher training: A practical guide. New York: The Haworth Press.

Alavi, M. (1994). Computer-mediated collaborative learning: An empirical evaluation. MIS Quarterly, June, 159-174.

Anderson, C. (1962). Technology in American education 1650-1900. New media for instruction 1, O.E. 34018. Bulletin 1962, No. 19, p. 53. U.S. Department of Health, Education and Welfare, Office of Education. Washington: Government Printing Office.

Bork, A. (1978). Computers as an aid to increasing physical intuition. American Journal of Physics, 46(8), 796-799.

Bork, A. (1987). Learning with personal computers. New York: Harper \& Row.

Bork, A. (1999). The Future of learning: An interview with Alfred Bork. Educom Review, 34(4), 24-27, 4850. Retrieved June 142001 from http://www.educause.edu/ir/library/html/erm/erm99/erm9946.html

Bork, A. (2000). Learning technology. Retrieved July 72005 from http://www.ics.uci.edu/ bork/educause review.htm

Cohen, E \& Boyd, E. (1999). Reengineering the university-Part II: A plan for overcoming the management information technology labor shortage. 1999 Annual Review of Communications, International Engineering Consortium, 233-236.

Debons, A. (1980). The information counselor. Journal of Information Counseling, 1(1), 6-12.

Department of Education of NSW, Australia (1987). Information Skills K-12. Curriculum Statement: (Draft).

Evans, N. (1986). The future of the microcomputer in schools. London: Macmillan Education Ltd.

Feenberg, A. (1990). Social factor research in computer-mediated communications. In L. M. Harasin (Ed.), Online education: Perspectives on a new environment (p. 69). New York: Praeger.

Garfield, F. (1979). 2001: An information society. Journal of Information Science, 1, 209-215.

Gilster, P. (1997). Digital literacy. New York: Wiley.

IEEE P1484.2 (2001). Learner model working group. Retrieved 2001 from the Web at http://tsc.ieee.org/wg2/index.html

Kirk, J. (1988). Information literacy and information technology. In Peter Alp (Ed.), Golden Opportunities, Proceedings of Six Australian Computers in Education Conference, Perth, Australia.

Knezevich, S. J. \& Frye, G. G. (Eds). (1970). Instructional technology and the school administrator. American Association of School Administrators.

Rami, A \& Gabriele, P. (2001). Virtual learning environment: An information technology basic skills course on the Web. Retrieved March 2, 2001 from the Web http://www.isworld.org/ais.ac.98/proceedingss/web teaching.htm

Rathswohl, E. J. (1990). Information resource management and the end user: Some implications for education. In Mehdi Khosrowpour (Ed.), Managing information resources in the 1990s. Proceedings of 1990 Information Resource Management Association International Conference, (p. 85). IDEA Group.

Steinberg, E. R. (1991). Teaching computers to teach. (2 ${ }^{\text {nd }}$ ed.). New Jersey: Lawrence Erlbaum Associates. 
Tianwei, X. (1999). Using computers in Chinese language teaching. Retrieved July 21, 2000 from http://www.csulb.edu/ txie/papers/Using_cpmputers.htm

Zhengsheng, Z. (1999). CALL for Chinese - Issues and practice. Retrieved June 13, 1999 from http://phllo.ucdavis.edu/ txie/learn_pnline/issues.htm

\section{Biography}

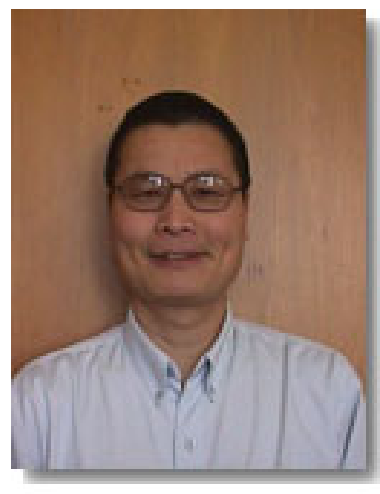

Tongtao Zheng is a professor and the Dean of Foundation College of Xiamen University, Fujian, China. He received his PhD in applied linguistics and information science from Australia National University and University of New South Wales in Australia. His current research interests include the application of information technology in education, second language acquisition, and online education theories. He has published 5 books and many papers in various journals in the areas of information science, education, psychology, linguistics, and culture. He can be contacted by email: tongtaoz@netscape.net or tongtao@jingxian.xmu.edu.cn. His postal address is: Foundation College, Xiamen University, Fujian, China 361005. 